\title{
Double-Blind Placebo Controlled Study of Thiamine and Cognitive Effect on Chronic Hemodialysis Patients
}

\author{
Isolda Prado de Negreiros Nogueira Maduro'*, Siane Prado Lima Souza², Alba Regina Jorge \\ Brandão $^{3}$ and Karla Cristina Petruccelli Israel ${ }^{3}$ \\ ${ }^{1}$ Department of Nutrition, Amazonas State University, Brazil \\ ${ }^{2}$ Department of Neurology, Hospital Universitário Getúlio Vargas, Brazil \\ ${ }^{3}$ Department of Nephrology, Centro de Doenças Renais do Estado do Amazonas, Brazil
}

\begin{abstract}
Introduction: This study proposed to assess cognitive function against the use of thiamine $v s$. placebo in patients undergoing Chronic Hemodialysis (CHD) because this group commonly presents risks of losses of vitamins and other nutrients related to dialysis procedure.
\end{abstract}

Methods: In a double-blind study, 32 patients (12 female/16 male, $55.8 \pm 10.10$ years) submitted to CHD were recruited underwent collection of blood lactate (changed values above $2.0 \mathrm{mMol} / \mathrm{L}$ ), Mini-Mental State Exam (MMSE) (changed values score 24 points). Patients were randomly divided into four groups receiving thiamine $300 \mathrm{mg}$, thiamine $600 \mathrm{mg}$, placebo and control (no vitamin or placebo), during one month. Excluding those using multivitamins, thiamine or cholinergic replacement therapy, patients with respiratory failure, acute coronary insufficiency, unconscious, pregnancy, and indigenous ethnicity, younger than 18 years. Blood lactate and MMSE were assessed before and after the study.

OPEN ACCESS

*Correspondence:

Isolda Prado de Negreiros Nogueira

Maduro, Department of Nutrition,

Amazonas State University, School of Health Sciences (ESA), Avenida Carvalho Leal, 1777, Cachoeirinha, Manaus, Amazonas, CEP: 69065-00,

Brazil, Tel: +55 9238784363;

E-mail: isoldaprado@yahoo.com.br

Received Date: 16 Jan 2020

Accepted Date: 19 Feb 2020

Published Date: 24 Feb 2020

Citation:

de Negreiros Nogueira Maduro IP, Lima Souza SP, Jorge Brandão AR,

Petruccelli Israel KC. Double-Blind

Placebo Controlled Study of Thiamine and Cognitive Effect on Chronic Hemodialysis Patients. Ann Chron Dise. 2020; 3(1): 1006

Copyright (C) 2020 Isolda Prado de Negreiros Nogueira Maduro. This is an open access article distributed under

the Creative Commons Attribution

License, which permits unrestricted use, distribution, and reproduction in any medium, provided the original work is properly cited.
Findings: Thiamine supplementation (300 $\mathrm{mg}$ or $600 \mathrm{mg}$ ) during one month did not interfere with MMSE in groups or within groups. Groups before $v s$. after: control group $27.6 \pm 1.6$ vs. $27.7 \pm 1.9$ (ns); placebo group $26.7 \pm 1.8$ vs. $27.0 \pm 1.7$ (ns); thiamine $300 \mathrm{mg}$ group $27.3 \pm 1.1$ vs. $27.8 \pm 1.6$ (ns), thiamine $600 \mathrm{mg}$ group $26.4 \pm 1.0$ vs. $26.8 \pm 1.3$ (ns). Moreover, lactate values were not altered during the study.

Discussion: The results suggests no cognitive interfere for patients on chronic hemodialysis with $300 \mathrm{mg}$ or $600 \mathrm{mg}$ of thiamine for 1 month compared with placebo or control groups. Studies with longer duration or the active form of the vitamin should be tested further.

Keywords: Thiamine; Dialysis; Mini-mental; Cognition; Lactate

\section{Introduction}

Thiamine (or Vitamin B1) is an essential compound in metabolic reactions indispensable for the maintenance of a healthy life. As a water soluble vitamin, thiamine is absorbed through diffusion and active transport at the jejunum and the ileum, where it is metabolized by phosphorylation at the intestinal wall into thiamine pyrophosphate, its active form and co-factor to important enzymatic complexes [1]. Thiamine deficiency has four classic presentations: Painful (or painless) peripheral motor-sensitive polyneuropathy, affecting mainly the distal limbs (dry beriberi); sodium retention, vasodilation and water retention, resulting in high cardiac output, edema and bilateral ventricular dysfunction (chronic wet beriberi); acute wet beriberi, associated to myocardial lesion and circulatory shock (Shoshin-beriberi) and Wernicke encephalopathy, characterized by ataxia, motor ocular dysfunction, mental confusion, amnesia, learning disability and confabulation (Korsakoff's encephalopathy) [2].

These clinical manifestations are frequently noticed in populations which main dietary component is cassava or its flour, polished or grounded rice, and wheat flour, therefore thiamine poor food [3]. Another important cause of thiamine deficiency occurs in chronic conditions as for End Stage Renal Disease (ESRD) patients undergoing Renal Replacement Therapy (RRT) [4]. Malnutrition is a common feature in ESRD patients for a number of reasons: anorexia, inadequate diet, hypercatabolism, protein-energy wasting, and loss of nutrients through dialysis membranes (particularly amino acids and water-soluble vitamins), chronic inflammation, dialysis inadequacy 
and bioincompatible membranes [5-8].

The purpose of the present double-blind study was to evaluate the cognitive responses of daily oral thiamine supplementations on $300 \mathrm{mg}$ and $600 \mathrm{mg}$ doses when compared to placebo, in a group of patients who do not necessarily have cognitive impairment, who were enrolled on regularly chronic dialysis program and not yet have been received vitamin supplementation, as this group is at high risk of vitamin losses and nutritional deficiency related to RRT. Thus, the aim of the study would be to verify the impact of thiamine supplementation in two different doses, using the mini-mental state examination, a "popular" tool to assess cognitive status. In addition, our study also sought to verify indirect measures of serum thiamine increase (serum lactate decrease) [9].

\section{Materials and Methods}

\section{Patient enrollment}

A double-blind prospective study was conducted on patients recruited at the Centro de Doenças Renais do Estado do Amazonas (CDR). The Research Ethics Committee of Amazonas State University, Amazonas, Brazil, approved the study and the patients gave written informed consent to participate. Inclusion criteria were: Patients who had been on CHD for at least 6 months, older than 18 years, with no upper age limit; using a biocompatible Hemodialysis (HD) membrane (Fresenius Medical Care ${ }^{\mathrm{Tx}}$, F5, F6, F7 or F8, Germany), with $\mathrm{Kt} / \mathrm{V} 1.3$, and who were on a thrice-weekly low-flux HD program. Active infectious disease, cancer, respiratory failure, acute coronary insufficiency, unconsciousness, pregnancy, use of steroids, thiamine in similar doses or cholinergic replacement therapy, previous adverse effects on thiamine supplementation, indigenous ethnicity, were exclusion criteria. The patients were allowed to keep up with their usual multivitamin supplements since these had lower doses of thiamine if compared to those prescribed on the study. The present protocol did not interfere with any medical routine.

\section{Experimental design}

Thirty-two patients who voluntarily participated in the study were first selected by clinical evaluation and maintained on their respective dialysis shift routine. The patients had their cognitive status initially evaluated through the Mini-Mental State Examination (MMSE). MMSE is divided in seven parts, including temporal orientation, spatial perception, recent memory, calculus, attention, evocation, language and visual construction. The researchers used a version of MMSE validated for Brazilian patients [10,11]. The cutoff was 24 points for individuals with more than 8 school years and 17 points for patients with less than 8 school years (scores at MMSE vary from 0 to 30 points). After the MEEM, patients were randomly assigned to four groups of eight members each. Group I received red and white pills weighting $600 \mathrm{mg}$; Group II received green and white pills (600 mg); Group III received totally white pills, weighting 600 $\mathrm{mg}$ and the control group did not receive any pills. The medication was kept for thirty days and the outcome was change in MMSE levels. At the beginning (BASAL) and at the final of experiment (FINAL), all patients were submitted to clinical evaluation by anamnesis and physical examination. Evaluation of nutritional status according to anthropometric data was performed at the end of dialysis, including weight, height and Body Mass Index (BMI) determined according to post-dialysis weight, with values $<18.5 \mathrm{~kg} / \mathrm{m}^{2}$ considered to indicate low weight [12]. On each occasion all groups were also submitted to analysis of the blood levels of lactate (reference $0.8 \mathrm{mmol} / \mathrm{L}$ to 2.0 $\mathrm{mmol} / \mathrm{L}$ ), an indirect measure of thiamine action. All groups received an adherence check chart to confirm the daily doses.

The participants were observed during dialysis and were instructed to report minor changes such as mood swings, appetite, or any other complaints, while routine clinical laboratory tests continued to be performed throughout the study. The meaning of the colors of the pills was registered and sealed in an envelope, to be revealed only at the end of the study. Thus, Group I received $300 \mathrm{mg}$ of thiamine in $600 \mathrm{mg}$ pills, Group II received $600 \mathrm{mg}$ of thiamine and group III received $600 \mathrm{mg}$ of starch (placebo).

Data were reported as means $\pm \mathrm{SD}$. Within-group BASAL data were compared to FINAL data by the paired " $\mathrm{t}$ " test, and betweengroup data were compared by the " $t$ " test. Percentages were compared by the $\chi^{2}$ test. The level of significance was set at $p \leq 0.05$.

\section{Results and Discussion}

Twenty-eight patients (of 32 recruited) completed the study, divided in four groups of seven components. There were 12 women and 16 men, ages varying between 37 and 74 years old $(55.78 \pm$ 10.11), with no significant difference between groups regarding their demographic aspects, beside the variation of patients ages between groups. No major clinical events were observed during dialytic therapy throughout the study.

As for the nutritional status of the study groups, we found a mean BASAL BMI of $22.64 \mathrm{~kg} / \mathrm{m}^{2} \pm 3.26 \mathrm{~kg} / \mathrm{m}^{2}$, witch $14.28 \%$ of the patients where underweight $\left(\mathrm{BMI}<18.5 \mathrm{~kg} / \mathrm{m}^{2}\right) ; 17.85 \%$ were overweight and $67.85 \%$ were eutrophic $(\mathrm{p}<0.05)$. There was no difference regarding the anthropometric data between the beginning and the end of the study.

According to the MMSE evaluation for the cognitive status of the participants, there were no significant variations indicating cognitive alterations in response to the use of thiamine in any dose or placebo. The results for these evaluations in each group can be seen in Table 1.

The blood levels of lactate were similar and stable in all groups, with no significant differences between the stages of the study, as shown in Table 2.

Thiamine deficiency can lead to peripheral nerve degeneration. In some occasions, it may result in brain damage, some these of

Table 1: Comparison of the MMSE punctuations between the groups, at the beginning and the end of the study.

\begin{tabular}{|l|c|c|c|}
\hline \multicolumn{1}{|c|}{ Groups } & AGE Year & BASAL MMSE score & FINAL MMSE score \\
\hline Group I Thiamine $300 \mathrm{mg}$ & $55.4 \pm 10.8$ & $27.3 \pm 1.1$ & $27.8 \pm 1.6$ \\
\hline Group II Thiamine $600 \mathrm{mg}$ & $58.8 \pm 7.9$ & $26.4 \pm 1.0$ & $\mathrm{~ns}$ \\
\hline Group III Placebo & $51.4 \pm 12.9$ & $26.7 \pm 1.8$ & $\mathrm{~ns}$ \\
\hline Group IV Control & $57.4 \pm 8.6$ & $27.6 \pm 1.6$ & $\mathrm{~ns}$ \\
\hline p-value & P<0.05 Group II vs. Group III & $\mathrm{ns}$ & $\mathrm{ns}$ \\
\hline
\end{tabular}

MMSE: Mini-Mental State Examination 
Table 2: Blood levels of lactate according to stages of the study.

Table 2: Blood levels of lactate according to stages of the study.
\begin{tabular}{|l|c|c|}
\hline \multicolumn{1}{|c|}{ Groups } & BASAL Lactate (mmol/L) & FINAL Lactate (mmol/L) \\
\hline Group I Thiamine $300 \mathrm{mg}$ & $0.95 \pm 0.07$ & $0.90 \pm 0.04$ \\
\hline Group II Thiamine $600 \mathrm{mg}$ & $0.94 \pm 0.04$ & $0.9 \pm 0.04$ \\
\hline Group III Placebo & $0.92 \pm 0.07$ & $0.95 \pm 0.07$ \\
\hline Group IV Control & $0.91 \pm 0.09$ & $0.92 \pm 0.05$ \\
\hline p-value & $\mathrm{ns}$ & $\mathrm{ns}$ \\
\hline
\end{tabular}

Lactate, reference values $(0.8 \mathrm{mmol} / \mathrm{L}$ to $2.0 \mathrm{mmol} / \mathrm{L})$.

irreversible nature as in dry Beriberi and in Wernicke-Korsakov's Syndrome, where myelinic degeneration leads to symptoms that may decrease with treatment but generally rebound a short time after, because thiamine supplementation does not cure established lesions, it only prevents further demyelination [13]. The present study was developed in a group of chronic dialysis patients, at risk of nutrient loss [14]. There is a well-established relation between thiamine deficiency and impaired cognitive function. The hypothesis made was that losses of thiamine in the dialysate could result in a cognitive deficit, detectable through the chosen analysis instrument, MMSE. Thus, the blinded test of thiamine supplementation would alter the scores in the test. So, we assessed the mental status of the four groups of patients through MMSE. The groups were randomly assigned to receive pills similar in weight, but with different compositions (300 $\mathrm{mg}$ of thiamine, $600 \mathrm{mg}$ of thiamine and $600 \mathrm{mg}$ of starch). There was also a group which was assigned to receive no pills, control group.

In the present study, as reported previously by our group [6], around $14 \%$ of the CHD patients showed signs of malnutrition, like BMI below $18.5 \mathrm{~kg} / \mathrm{m}^{2}$. The data specific for the patients in RRT, however, demands a BMI over $23 \mathrm{~kg} / \mathrm{m}^{2}$ to exclude cachexia and muscular wasting due to the dialysis procedure [15]. Both malnutrition and cachexia may occur by low protein-energy ingestion, as a consequence of reduced assimilation or utilization of nutrients or due to hyper catabolism and systemic inflammation, highly prevalent amongst ESRD patients, even at the start of RRT [16].

Thus, $50 \%$ of the patients enrolled in this study were under this cutoff point, although there was no difference between groups I and II even after thiamine supplementation. Since thiamine deficiency can lead to anorexia, supplementation could lead to appetite increased, with gain in weight following supplementation. Unfortunately, due to the brevity of the supplementation we did not observe the weight gain $[17,18]$

The relation of high blood lactate levels and low total thiamine blood levels are well documented [9], which is directly linked to important step of glucose aerobic metabolism. As coenzyme thiamine pyrophosphate, this vitamin acts together with pyruvate dehydrogenase, an enzymatic complex responsible for pyruvate oxidative decarboxylation and consequent formation of acetyl Coenzyme A (acetyl CoA). This vitamin deficiency can lead to decreases of pyruvate to acetyl-CoA conversion, increasing intracellular lactate [19]. But data regarding thiamine deficiency in ESRD and RRT patients are controversial [20,21]. Case reports portray series of patients with several clinical manifestations, including Beriberi and Wernicke's encephalopathy in non-alcoholic subjects, while other data do not support any evidence that there's chronic reduction of thiamine levels in RRT patients [20,21]. In this scenario, patients submitted to a regular schedule of $15 \mathrm{~h}$ of dialysis per week could not suffer significant losses of thiamine through dialysate [22].
MMSE are probably the more broadly used test to evaluate cognitive status worldwide. The test consists in a sequence of questions grouped in seven categories, each one chosen in order to check a particular function as known temporal orientation (5 points), spatial orientation ( 5 points), word registry ( 3 points), attention and calculus ( 5 points), word recall ( 3 points), language ( 8 points) visual constructive capacity ( 1 point). The score goes from a minimum of 0 to a maximum of 30 points, corresponding to minimum and maximum level of cognitive capacity, usually used in elderly persons. The most frequently used cutoff is 24 points, although variations are proposed according to level of schooling. In this study the MMSE scores during thiamine supplementation, placebo use and in the control group did not vary in the testing month, either into or between the groups. The mean MMSE score levels were below the cutoff point for cognitive deficit in this population, despite the variation of ages of patients between the groups of study $[10,11]$.

The results of this study suggest that $300 \mathrm{mg}$ or $600 \mathrm{mg}$ thiamine supplementation did not interfere with MMSE scores, but was not high at the beginning of supplementation.

However, there were significant improve of humor and in the perception of well-being, in a rapid period of administration of thiamine $600 \mathrm{mg}$. Data noticeable after the use of thiamine for a period of time larger than 3 months to a year, with no clear improve of cognitive function [22]. Studies with longer duration or the active form of the vitamin should be tested further, for more evident results $[23,24]$. The results suggest no cognitive interference for patients on chronic hemodialysis with $300 \mathrm{mg}$ or $600 \mathrm{mg}$ of thiamine for 1 month compared with placebo or control groups. Studies with longer duration or the active forms of the vitamin should be tested further.

\section{Acknowledgment}

This work was supported by Fundação de Amparo à Pesquisa do Estado do Amazonas (FAPEAM).

\section{References}

1. Iucif JN, Vannucchi H, Credidio EV. Vitamins: Nutrologic approach in use and abuse. Antonio Carlos Lopes. Diagnosis and Treatment. $1^{\text {st }} \mathrm{ed}$. Manole; 2009. p.484-512.

2. Sechi G, Serra A. Wernicke's encephalopathy: New clinical settings and recent advances in diagnosis and management. Lancet Neurol. 2007;6(5):442-55.

3. BRASIL. Ministério da Saúde. Guia de Consulta para Vigilância Epidemiológica, Assistência e Atenção Nutricional dos Casos de Beribéri/ Ministério da Saúde.[Guide for Consultation on Epidemiological Surveillance, Nutrition Assistance and Care of the Cases of Beriberi/ Ministry of Health.]Secretaria de Atenção à Saúde. Secretaria Especial de Saúde indígena. Secretaria de Vigilância em Saúde. Brasília: Ministério da Saúde, 2012. Portuguese.

4. Calegari A, Barros EG, Veronese FV, Thomé FS. Malnourished patients 
on hemodialysis improve after receiving a nutritional intervention. J Bras Nefrol. 2011;33(4):394-401.

5. Pupim LB, Majchrzak KM, Flakoll PJ, Ikizler TA. Intradialytic oral nutrition improves protein homeostasis in chronic hemodialysis patients with deranged nutritional status. J Am Soc Nephrol. 2006;17(11):3149-57.

6. Prado de Negreiros Nogueira Maduro I, Elias NM, Nonino Borges CB, Padovan GJ, Cardeal da Costa JA, Marchini JS. Total nitrogen and free amino acid losses and protein calorie malnutrition of hemodialysis patients: Do they really matter? Nephron Clin Pract. 2007;105(1):c9-17.

7. Stenvinkel P, Barany P, Chung SH, Lindholm B, Heimbürger O. A comparative analysis of nutritional parameters as predictors of outcome in male and female ESRD patients. Nephrol Dial Transplant. 2002;17(7):126674.

8. Chiarello PG, Vannucchi MT, Vannucchi H. Hyperhomocysteinemia and oxidative stress during dialysis treatment. Ren Fail. 2003;25(2):203-13.

9. Althoff MEWS, Alcântara GV, Souza CC, Camilo FDJ, Liberali R, Navarro AC, et al. Effect of thiamine supplementation on lactate concentration in professional soccer players. Revista Brasileira de Nutrição Esportiva. 2009;3(16):277-85

10. Benton D, Fordy J, Haller J. The impact of long-term vitamin supplementation on cognitive functioning. Psychopharmacology (Berl). 1995;117(3):298-305.

11. De Melo DM, Barbosa AJ. The use of Mini-Mental State Examination in research on the elderly people in Brazil: a systematic review. Ciên Saúde Colet. 2015;20(12):3865-76.

12. O'Bryant SE, Humphreys JD, Smith GE, Ivnik RJ, Graff-Radford NR, Petersen RC, et al. Detecting dementia with the mini-mental state examination in highly educated individuals. Arch Neurol. 2008;65(7):9637.

13. Maduro IP, Nonino CB, Sakamoto LM, Meirelles MG, Cardeal Da Costa JA, Marchini JS. Red meat snacks for chronic hemodialysis patients: effect on inflammatory activity (a pilot study). Ren Fail. 2013;35(6):830-4.

14. Gibson GE, Blass JP. Thiamine-dependent processes and treatment strategies in neurodegeneration. Antioxid Redox Signal. 2007;9(10):160519.
15. Heinz J, Domröse U, Westphal S, Luley C, Neumann KH, Dierkes $\mathrm{J}$. Washout of water-soluble vitamins and of homocysteine during haemodialysis: Effect of high-flux and low-flux dialyser membranes. Nephrology (Carlton). 2008;13(5):384-9.

16. Ikizler TA, Cano NJ, Franch H, Fouque D, Himmelfarb J, Kalantar-Zadeh $\mathrm{K}$, et al. Prevention and treatment of protein energy wasting in chronic kidney disease patients: a consensus statement by the International society of renal nutrition and metabolism. Kidney Int. 2013;84(6):1096-107.

17. Liu M, Alimov AP, Wang H, Frank JA, Katz W, Xu M, et al. Thiamine deficiency induces anorexia by inhibiting hypothalamic AMPK. Neuroscience. 2014;267:102-13.

18. Smidt LJ, Cremin FM, Grivetti LE, Clifford AJ. Influence of thiamin supplementation on the health and general well-being of an elderly Irish population with marginal thiamin deficiency. J Gerontol. 1991;46(1):M1622.

19. Ou SM, Chen YT, Hung SC, Shih CJ, Lin CH, Chiang CK, et al. Association of estimated glomerular filtration rate with all-cause and cardiovascular mortality: The role of malnutrition-inflammation-cachexia syndrome. J Cachexia Sarcopenia Muscle. 2016;7(2):144-51.

20. Leite HP, de Lima LF. Metabolic resuscitation in sepsis: a necessary step beyond the hemodynamic? J Thorac Dis. 2016;8(7):E552-7.

21. Ubukata M, Amemiya N, Nitta K, Takei T. Serum thiamine values in endstage renal disease patients under maintenance hemodialysis. Int J Vitam Nutr Res. 2015;85(5-6):348-55.

22. Kimura H, Takeda K, Muto Y, Mukai H, Furusho M, Nakashita S, et al. Development of Wernicke's encephalopathy during initiation of hemodialysis in an elderly non-alcoholic patient. Clin Nephrol. 2012;78(6):487-91.

23. Kittanamongkolchai W, Leeaphorn N, Srivali N, Cheungpasitporn W. Beriberi in a dialysis patient: Do we need more thiamine? Am J Emerg Med. 2013;31(4):753.

24. Kihm LP, Müller-Krebs S, Klein J, Ehrlich G, Mertes L, Gross ML, et al. Benfotiamine protects against peritoneal and kidney damage in peritoneal dialysis. J Am Soc Nephrol. 2011;22(5):914-26. 